\title{
Validação de método analítico para determinação de Ocratoxina A em amostras de grãos de café verde provenientes da Região de Chiriquí/Panamá, empregando LC-AJS-MS/MS
}

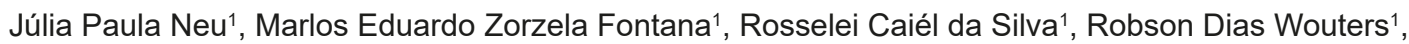 \\ Eira Mercedes Sobenis Quintero ${ }^{2}$, Carmen Dickow Cardoso ${ }^{1}$, Simone Noremberg Kunz ${ }^{1}$; lonara Regina Pizzutti ${ }^{1}$
}

\begin{abstract}
Resumo
O presente trabalho descreve a validação de um método e sua aplicação para determinação de Ocratoxina A, em amostras de grão de café verde, procedentes do Panamá, empregando LC-AJS-MS/MS. Antes da extração, as amostras de café foram moídas e, em seguida, empastadas com água (s/urry). Foi realizado um estudo de validação completo para garantir o desempenho adequado do método de extração e cromatográfico. As amostras foram fortificadas em 3 níveis de concentração com Ocratoxina $A$ (7 repetições em cada nível, $n=7$ ) e então submetidas ao procedimento de extração usando como solvente uma solução de ácido acético $1 \%$ em acetonitrila. Antes da análise cromatográfica, os extratos foram diluídos em acetonitrila: água (1:1 v/v), a fim de melhorar o desempenho cromatográfico dos analitos e reduzir o efeito matriz. Soluções padrão foram preparadas em solvente orgânico e em extrato de café em branco, em 7 níveis de concentração e analisadas 7 vezes cada. O método foi avaliado quanto à exatidão (\% de recuperação), precisão (RSD\%), seletividade, linearidade $\left(r^{2}\right)$, limite de quantificação (LQ) e efeito matriz (\%). Não foi encontrada Ocratoxina A em nenhuma das 50 amostras de grãos de café analisadas.
\end{abstract}

Palavras-chave: Validação; Café; Ocratoxina A; LC-AJS- MS/MS

\section{Introdução}

Mundialmente, o café tornou-se a segunda bebida quente mais consumida, posição privilegiada que pode ser explicada pela grande variedade de compostos químicos presentes no café que proporcionam uma mistura única de propriedades sensoriais (GALARCE-BUSTOS et al., 2014). O aumento do consumo de café também foi relacionado aos seus benefícios para a saúde, como uma redução no risco de câncer de fígado e cólon, cálculos biliares, cirrose hepática e doença de Parkinson, que são, frequentemente, associados às suas propriedades antioxidantes (ESPINELLI JUNIOR et al., 2020).

Na preparação das bebidas à base de café, utiliza-se principalmente o grão torrado ou moído. No entanto, as propriedades funcionais das bebidas de café estão atualmente dando origem ao desenvolvimento de novos mercados que comercializam produtos formulados alternativos com base no extrato de grãos de café verde e seus constituintes bioativos (RIBEIRO et al., 2021).

A América Latina é responsável por $48 \%$ da produção mundial de café. No entanto, culturas agrícolas de clima tropical estão mais sujeitas ao desenvolvimento fúngico. As micotoxinas são substâncias de baixa massa molecular pertencentes a diversos classes químicas, produzidas por metabólitos secundários de fungos, e que podem causar efeitos toxicológicos em animais e seres humanos (BARBOSA, 2019). Estima-se que cerca de $25 \%$ de todos os produtos agrícolas do mundo estejam contaminados por tais substâncias. Existem cerca de 300 a 400 micotoxinas com estruturas muito diversificadas de que resultam diferentes propriedades químicas e físico-químicas.
As ocratoxinas são produzidas principalmente por fungos do gênero Aspergillus sp. e Penicillium sp., naturalmente presentes em cereais, café, cacau, uva e soja, entre outros (OMOTAYO et al., 2019). Neste grupo a forma mais relevante e prevalente é a ocratoxina A (OTA).

Vários fatores como temperatura, atividade da água e a composição do meio podem favorecer o crescimento de fungo, e produzir OTA em diversas concentrações; a contaminação pode ocorrer em várias etapas, desde a colheita no campo até o armazenamento do produto, bem como a fermentação e a secagem.

A estabilidade da OTA a altas temperaturas e acidez fazem com que a presença dessa micotoxina nos alimentos seja preocupante, justamente por ser resistente ao processamento como cozimento, tostagem e fermentação, ou seja, uma vez que o alimento esteja contaminado é difícil a sua remoção.

A toxicidade da OTA foi amplamente descrita na monografia da International Agency for Research on Cancer (IARC) em 1993, sendo classificada como possível carcinogênico humano. O principal efeito observado pela ingestão de OTA é o desenvolvimento de doenças nos rins, sendo fator contribuinte para o desenvolvimento da Nefropatia Endêmica dos Balcãs (BEN - Balkan Endemic Nephropathy). Estudos também tem revelado uma conexão com a exposição de OTA e câncer no fígado, rins, glândulas mamárias e testículos em animais (ANDRADE, 2016).

Devido ao risco potencial da OTAà saúde humana e animais, é de suma importância a existência de métodos para a determinação e quantificação desta substância. Em diferentes países, OTA tem

\footnotetext{
1 Universidade Federal de Santa Maria (UFSM) - Departamento de Química, Centro de Pesquisa e Análise de Resíduos e Contaminantes (CEPARC). Avenida Roraima 1000 - prédio 18, Santa Maria-RS, Brasil. (55)3220-9458. E-mail: ionara.pizzutti@ceparc.com.br.

2 Universidad Autónoma de Chiriquí, Panamá.
} 
sido detectada tanto em grãos de café verde quanto torrado. Embora o café verde seja torrado a altas temperaturas, a OTAnão é completamente destruída, e sua presença tem sido detectada em café torrado e moído, café instantâneo, café descafeinado, e ainda mais importante, no café pronto para beber (YOUG et al., 2019).

O objetivo deste estudo foi validar um método analítico, empregando LC-AJS-MS/MS, para avaliar a qualidade de 50 amostras de grãos de café verde provenientes de produtores rurais da região de Chiriqui, Panamá, quanto à presença de OTA. A importância deste estudo deve-se ao fato do Panamá exportar café para diversos países, logo, o mesmo deve atender a qualidade fitossanitária do país importador.

\section{Material e métodos}

As amostras de grãos de café verde foram obtidas de produtores de café em Boquete, na região de Chiriqui/Panamá. Após a amostragem, uma subamostra de $200 \mathrm{~g}$ foi enviada ao laboratório. Primeiramente, realizou-se a pesagem $100 \mathrm{~g}$ de grãos de café verde, triturou-se em um moinho de facas até virar café moído e adicionou-se $300 \mathrm{~g}$ de água ultra pura em uma proporção de 1:3 $(\mathrm{m} / \mathrm{m})$, para uma total homogeneização e formação de uma da pasta (s/urry).

Após este processo, foi pesado $10 \mathrm{~g}$ de slurry, em tubos de centrífuga de $50 \mathrm{~mL}$ de PTFE. Amostras em branco foram fortificadas com OTA nas concentrações 2,5 e $20 \mathrm{\mu g} \mathrm{kg}^{-1}$, com 7 repetições em cada concentração. Para controle do procedimento de extração, foi utilizado quinalfós $\left(25 \mathrm{ng} \mathrm{mL}^{-1}\right)$ como padrão interno (PIS). Após, foram adicionados $10 \mathrm{~mL}$ de solução de ácido acético $1 \%$ em acetonitrila, e os frascos agitados no vórtex por $1 \mathrm{~min}$. Para remover a água foram adicionados $3 \mathrm{~g}$ de $\mathrm{MgSO} 4$ anidro e novamente agitação por $1 \mathrm{~min}$. Em seguida os tubos foram centrifugados a $4000 \mathrm{rpm}$ durante $4 \mathrm{~min}$. Posteriormente, em vials, foi adicionado uma alíquota de $500 \mu \mathrm{L}$ do extrato de café contendo OTAe diluído com $500 \mu \mathrm{L}$ de uma solução de acetonitrila:água (1:1 v/v) contendo propoxur $\left(20 \mathrm{ng} \mathrm{mL}^{-1}\right)$, como padrão interno do instrumento, seguindo da determinação cromatográfica.

A determinação cromatográfica da OTA foi conduzida por LC-AJS- MS/MS, utilizando uma coluna analítica infinityLab poroshell $120 \mathrm{EC}-\mathrm{C} 18(2,7 \mu \mathrm{m})(2,1 \mathrm{~mm} \times 100 \mathrm{~mm})$ com um pré coluna UHPLC GUARD 3pK infinityLab poroshell 120 EC-C18 $(2,7 \mu \mathrm{m})(2,1 \mathrm{~mm} \times 5 \mathrm{~mm})$. Para a separação cromatográfica a fase móvel consistiu em água ultrapura com $0,1 \%$ de ácido fórmico (eluente $\mathrm{A}$ ) e acetonitrila com $0,1 \%$ de ácido fórmico (eluente B). Aeluição do gradiente começou com $80 \%$ do eluente $A$, seguido por um gradiente linear até $10 \%$ do eluente $A$ em 5 min, mantido até 9 min e depois a $10 \%$ do eluente A; novamente fez-se um gradiente linear de $95 \%$ do eluente $A$ em 0,25 min, e manteve-se até os $11 \mathrm{~min}$, retornando o gradiente em tempo iniciais até os $14 \mathrm{~min}$, e mantido por mais $2 \mathrm{~min}$. A vazão da fase móvel foi $300 \mu \mathrm{L} \mathrm{min}{ }^{-1}$. O volume de injeção foi de $2 \mu \mathrm{L}$. Para obtenção da resolução máxima, a temperatura da coluna foi de $45^{\circ} \mathrm{C}$. Nitrogênio foi utilizado como gás de dessolvatação e de colisão. Espectrômetro de massa Ultivo, equipado com uma fonte de ionização da Jet Stream (AJS) (Agilent), operando no modo de íon positivo, foi utilizado para a aquisição de dados no modo de monitoramento de reação múltipla dinâmico (dMRM). $O$ tempo de retenção da OTA foi 7,26 min e a partir do íon precursor
404,1 foram monitorados os íons produtos de quantificação 220,9 e de confirmação 238,5 , os quais foram obtidos após a aplicação de uma energia de colisão de, respectivamente, 41 e $29 \mathrm{~V}$.

Para avaliar a linearidade e a faixa linear as soluções analíticas foram preparadas em solvente orgânico (acetonitrila contendo $1 \%$ de ácido acético e PIS) e em extrato de café em branco (matrix matched calibration) em 7 concentrações. A linearidade foi avaliada pelo cálculo dos coeficientes de determinação $\left(r^{2}\right)$ das curvas analíticas e utilizada para verificar a faixa linear dentro da faixa de concentração estudada. O efeito matriz, que pode ser definido como uma influência de um ou mais compostos co-extraídos da amostra na medição da concentração ou massa do analito e que é um parâmetro relacionado à seletividade do método analítico, foi calculado com base na inclinação da curva de calibração (slope) obtida a partir de solução padrão preparada em extrato do branco e em solvente orgânico (equação 1).

\section{$(X 1-X 2)$}

\section{$E M \%=\left[\frac{[}{X \mathbf{2}}-\mathbf{1}\right] \times \mathbf{1 0 0}$ Equação 01}

Onde:

X1 = inclinação da curva preparada em extrato branco de matriz X2= inclinação da curva preparada em solvente orgânico

Os experimentos de recuperação foram realizados para avaliar a precisão do método. Portanto, solução padrão de OTA em três níveis de concentração 2,5 e $20 \mu \mathrm{g} \mathrm{kg}^{-1}(\mathrm{n}=7$, cada concentração) foi adicionada a sete réplicas de amostras de slurry em branco. As amostras em branco também foram extraídas 7 vezes. Todas as amostras foram analisadas e as áreas dos picos cromatográficos foram utilizadas para avaliar a exatidão e precisão do método pelo cálculo da recuperação média (\%) e repetibilidade RSD\%, respectivamente.

\section{Resultados e Discussão}

Foi verificado para extratos de café em branco que nenhum pico de matriz foi detectado dentro de uma faixa de $\pm 0,1 \mathrm{~min}$ do tempo de retenção da OTA, em uma intensidade superior a $30 \%$ da resposta correspondente ao Limite de Quantificação ( LQ), demonstrando a seletividade do método. Este resultado comprova a seletividade do método e demonstra que este é adequado para esta finalidade. Para os dois padrões internos utilizados (quinalfós e propoxur) não foram observadas interferências em seus respectivos tempos de retenção.

Para a validação do método, a curva analítica que apresentou melhor linearidade foi aquela preparada a partir de soluções padrão em solvente orgânico, com $r^{2}$ de 0.9 .

O Limite de Deteç̧ão (LD) foi determinado a partir da injeção de soluções analíticas de baixa concentração, obtendo valor igual a $0,1 \mu \mathrm{kg}^{-1}$ para OTA. Considerando o LQ como igual a menor concentração que apresentou recuperações na faixa de $60-115 \%$ e RSD $\leq 21 \%$ (INMETRO, 2020), o método validado para OTA em grãos de café verde apresentou $L Q$ de $5 \mathrm{\mu g} \mathrm{kg}^{-1}$. A legislação brasileira preconiza apenas Limite Máximo Tolerado (LMT) de OTA para café torrado quer seja moído ou em grão, em café solúvel; atualmente o LMT brasileiro é de $10 \mathrm{\mu g} \mathrm{kg}^{-1}$ (BRASIL, 2021). Cabe ressaltar que, segundo o documento SANTE $n^{\circ} 12682 / 2019$, o LQ de um método deve ser igual ou menor ao LMT, sendo assim, o método desenvolvido apresenta resultados compatíveis com o 
preconizado pela legislação vigente. Estudos futuros serão realizados com grãos de café que passaram pela etapa de torrefação.

O efeito matriz (-8,7\%) obtido demonstrou que não é necessário levar em conta a supressão de sinal na hora da quantificação; esse resultado já era esperado, tendo em vista que nenhuma etapa de purificação do extrato foi efetuada para eliminar ou minimizar a presença e os efeitos dos constituintes de matriz.

A exatidão e precisão do método foram avaliadas por ensaios de fortificação e recuperação, a exatidão avaliada testando a exatidão, expressa como percentual média em 3 níveis de concentração, e a precisão expressa como a repetibilidade (RSD\%), para 7 repetições em cada concentração. Os percentuais de recuperação e RSD para OTA nas concentrações de 2,5 e $20 \mu \mathrm{g} \mathrm{kg}^{-1}$ foram de, respectivamente, $44 \pm 47 \%, 70 \pm$ $11 \%$ e $84 \pm 15 \%$. Na figura 1 , pode-se observar o cromatograma e o espectro de massas para OTA em grãos de café verde fortificados a $5 \mu \mathrm{g} \mathrm{kg}^{-1}$ (A) e solução padrão preparada em extrato branco de grãos de café verde na concentração de 0.625 ng $\mathrm{mL}^{-1}(B)$ que corresponde a concentração fortificada.

Resultados semelhantes para a OTA foram descritos por Reichert e colaboradores (2018), onde as concentrações validadas foram de 2, 5 e $10 \mu \mathrm{g} \mathrm{kg}^{-1}$, com o percentual de recuperação de, respectivamente, 59 ( $\pm 49 \%), 92( \pm 16 \%)$ e $90( \pm 10 \%)$. Assim, verificou-se que a concentração de $2 \mu \mathrm{g} \mathrm{kg}^{-1}$ não atendeu ao preconizado pelas orientações brasileiras sobre validação de métodos analíticos (DOCCGCRE-008) (INMETRO, 2020), desta forma, o método apresenta exatidão e precisão adequadas, a partir da concentração de $5 \mu \mathrm{g} \mathrm{kg}^{-1}$.

Após a validação do método, o mesmo foi aplicado para determinação de OTA em 50 amostras de grãos de café. Nenhuma das amostras analisadas apresentou resultados superiores ao LQ do método; desta forma, espera-se que após a torrefação dos grãos de café verde o mesmo apresente qualidade micotoxicológica adequada para o consumo.

\section{Conclusão}

A validação completa foi realizada para o método indicando não ser necessário nenhum tipo de tamponamento e ou etapa de cleanup subsequente, demonstrando assim praticidade no desempenho e redução na geração de resíduos. Assim, mesmo aplicado a uma matriz tão complexa como o café, o método apresentou excelentes resultados de exatidão e precisão, podendo ser utilizado paraanálises de rotina eficientes

\section{Referências}

ANDRADE, M. A. Determinação de Ocratoxina a em Vinho Utilizando Microextração em Fase Sólida no Tubo e Cromatografia Líquida de Alta Eficiência com Detecção por Espectrometria de Massas Sequencial. 90f. Dissertação (Mestrado), Instituto de Química, Universidade de São Paulo, São Carlos, 2016.

BARBOSA, A. C.; Desenvolvimento e Validação de uma Metodologia Analítica para Análise de Micotoxinas em Cerveja Utilizando QuEChERS e UHPLC-AJS-MS/MS. 112f. Dissertação (Mestrado), Departamento de Química Universidade Federal de Minas Gerais, Dissertação, Belo Horizonte/MG, 2019.
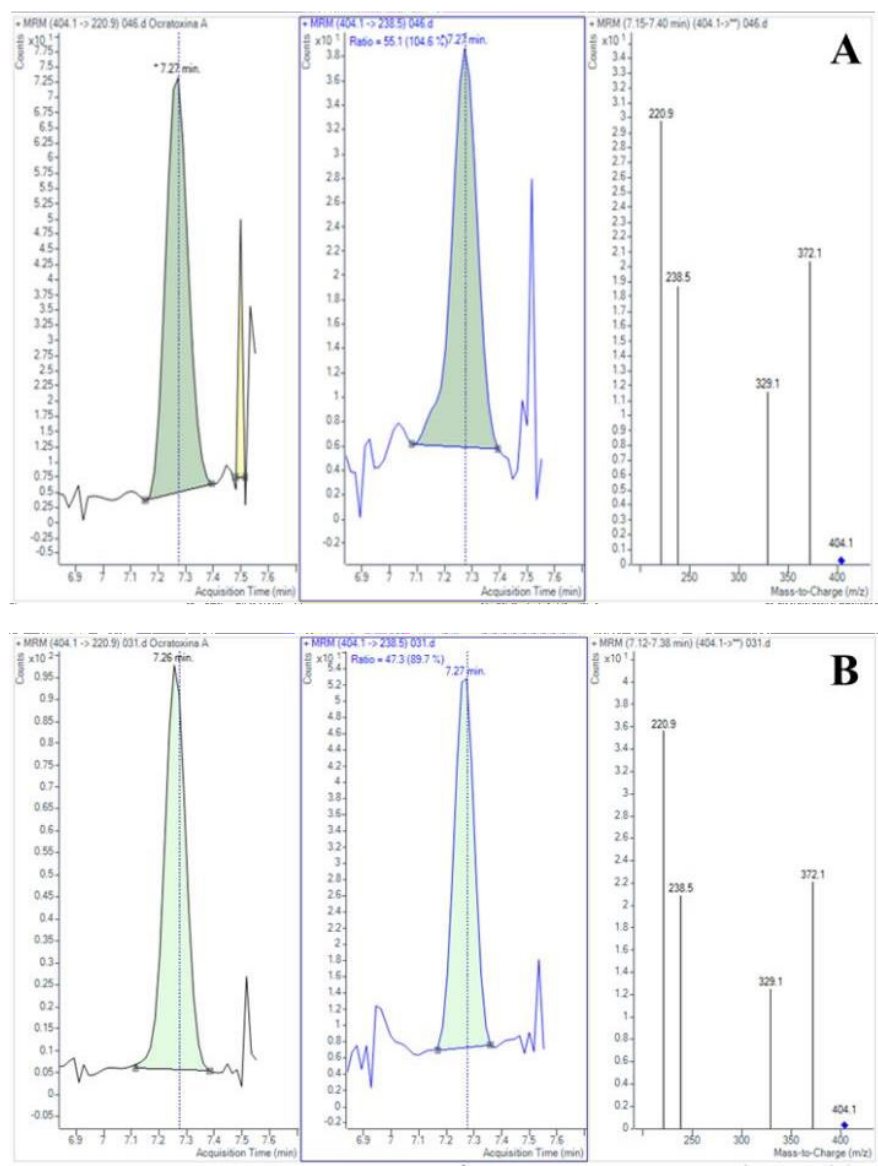

Figura 1: Cromatograma e espectro de massas para OTA em grãos de café verde (A) fortificado à $5 \mu \mathrm{g} \mathrm{kg}^{-1} \mathrm{e}(\mathrm{B})$ solução padrão preparada em extrato branco de grãos de café verde na concentração de $0.625 \mathrm{ng} \mathrm{mL}^{-1}$, correspondendo a concentração fortificada.

destinadas a pesquisas ou programas de monitoramento de OTA em grãos de café verde.

Quanto ao risco para a saúde do consumidor pela ingestão de OTA no café, mostra-se que cada vez mais estão sendo comercializados cafés de boa qualidade, pois provavelmente estão sendo adotadas medidas de controle fúngico a fim de que a produção de micotoxinas possa ser minimizada em toda a cadeia produtiva do café.

BRASIL. Ministério da Saúde/Agência Nacional de Vigilância Sanitária. Instrução Normativa - In $n^{\circ} 88$, de 26 de março de 2021. A Diretoria Colegiada da Agência Nacional de Vigilância Sanitária, no uso das atribuições que lhe confere o art. 15, III e IV, aliado ao art. $7^{\circ}$, III e IV da Lei $n^{\circ} 9.782$, de 26 de janeiro de 1999 , e ao art. 53, VII, $\S \S 1^{\circ}$ e $3^{\circ}$, do Regimento Interno aprovado pela Resolução de Diretoria Colegiada - RDC n² 255, de 10 de dezembro de 2018, resolve adotar a seguinte Instrução Normativa, conforme deliberado em reunião realizada em 25 de março de 2021, e eu, Diretor-Presidente, determino a sua publicação. Diário Oficial Da União, Brasília, DF, Edição 61. 31 mar. 2021. P.226. 
ESPINELLI JUNIOR, J. B. dos S., DA SILVA, G. V. B. M., BASTOS, R. B., FURLONG, E. B., CARAPELLI, R. Evaluation of the influence of cultivation on the total magnesium concentration and infusion extractability in commercial arabica coffee. Food Chemestry, v. 327, 2020 Oct 15; 327:127012. doi: 10.1016/j. foodchem.2020.127012.

GALARCE-BUSTOS, O.; ALVARADO, M.; VEGA, M.; ARANDA, $M$. Occurrence of ochratoxin A in roasted and instant coffees in Chilean market, Food Control, v. 46, p. 102-107, 2014. ISSN 0956-7135, https://doi.org/10.1016/j.foodcont.2014.05.014.

IARC. Monographs on the evaluation of carcinogenic risks to humans, v. 56, p. 445 - 466, 1993. Disponível em:< http:// monographs.iarc.fr/ENG/Monographs/vol56/mono56-16.pdf> Acesso em: 26 abril2021.

INMETRO. Orientação Sobre Validação de Métodos de Ensaios Químicos. Revisão 09, DOQ- CGCRE- 008, p. 1-30. Junho de 2020.

OMOTAYO, O. P., OMOTAYO, A. O., MWANZA, M., BABALOLA, O. O. Prevalência de micotoxinas e suas consequências na saúde humana. Toxicological Research, v. 35, n.1, p. 1-7, 2019. doi: 10.5487 / TR.2019.35.1.001.
REICHERT, B., KOK, A. de, PIZZUTTI, I. R., JOS SCHOLTEN, CARDOSO, C. D., SPANJER, M. Simultaneous determination of 117 pesticides and 30 mycotoxins in raw coffee, without clean-up, by LC-ESI-MS/MS analysis, Analytica Chimica Acta, v. 1004, p. 40-50, 0003-2670, 2018, https://doi.org/10.1016/j. aca.2017.11.077.

RIBEIRO, J. S., SALVA, T. de J. G., SILVAROLLA, M. B. Prediction of a wide range of compounds concentration in raw coffee beans using NIRS, PLS and variable selection, Food Control, v. 125, 2021, 107967, ISSN 0956-7135, https://doi. org/10.1016/j.foodcont.2021.107967.

SANTE. EUROPEAN COMMISSION DIRECTORATE GENERAL FOR HEALTH AND FOOD SAFETY. Analytical Quality Control and Method Validation for Pesticide Residues Analysis in Food and Feed (SANTE/12682/2019). Sante/12682/2019, p. 1-48, 2019.

YOUNG, G. D., RODRÍGUEZ, F. J., PIEDRA, J. S. Ocratoxina A en café. Revista Ciencia Y Salud, v.3, n.3, p. 21-26, 2019. https:// doi.org/10.34192/cienciaysalud.v3i3.65. 